\title{
Transferrin and iron movements in the rat conceptus during gestation
}

\author{
H. J. McArdle and E. H. Morgan \\ Raine Research Centre for Perinatal and Developmental Biology, Department of Physiology, \\ University of Western Australia, Nedlands, Western Australia 6009, Australia
}

\begin{abstract}
Summary. Transferrin binding by the placenta increased progressively from Day 14 to Day 21 of gestation. Qualitatively similar changes in the rate of iron transfer to the fetus were also seen. These results suggest that the increase in iron transfer to the fetus occurs as a result of an increase in the number of transferrin receptors on the maternal surface of the placenta rather than being due to a change in the affinity or turnover rate of the existing receptors, although disproportionate change in the number of receptors and maternal placental surface area suggests that there may be a reduction of the density of transferrin receptors. The ratios of fetal and total (fetal plus placental) iron to transferrin showed that maturation of the mechanism of iron release from transferrin and the intra-placental iron transport system occurred during development. In contrast to that in the chorioallantoic placenta, iron and transferrin incorporation into the yolk sac decreased during gestation, indicating that the yolk sac does not have a physiological role in the transport of iron from the mother to the fetus in the last part of pregnancy. For at least $28 \mathrm{~h}$ after fetectomy, the placenta continued to accumulate iron at the same rate as the controls. The iron thus accumulated was stored mainly as insoluble haemosiderin, and was not refluxed into the maternal circulation. These results indicate that iron transport by placental cells is 'preprogrammed' and is not subject to feedback control by the fetus or the placenta itself.
\end{abstract}

\section{Introduction}

In animals that have a haemochorial type of placenta (e.g. man, rat, rabbit and guinea-pig) materno-fetal iron transfer occurs across the chorioallantoic placenta (Vosburgh \& Flexner, 1950; Bothwell, Pribilla, Mebust \& Finch, 1958; Glasser, Wright \& Heyssel, 1968; Fletcher \& Suter, 1969; Seal, Sinha \& Doe, 1972). The rate of iron transfer increases rapidly during the last third of gestation and keeps pace with fetal growth (Nylander, 1953; Hershko, Cohen \& Zajicek, 1976). Near term, the process is unidirectional and appears to occur against a concentration gradient (Bothwell et al., 1958; Baker \& Morgan, 1970; Wong \& Morgan, 1973). Consequently, it is generally thought that iron is transferred by an active transport process. The first step in transfer is the binding of maternal transferrin to receptors on the membranes of the trophoblast cells lining the maternal blood spaces (Baker \& Morgan, 1970; Wong \& Morgan, 1973; van Bockxmeer, Hemmaplardh \& Morgan, 1975; Loh, Higuchi, van Bockxmeer, Smith \& Brown, 1980). The iron is then detached from the maternal transferrin, which returns to the maternal circulation, and is transferred to the fetal blood, where it binds to fetal transferrin. Although the main steps in the transfer process are recognized, the mechanisms responsible for the increase in rate of iron transfer during gestation and for the active nature of the process have not been elucidated. Presumably, an increase 
in the rate of placental iron transfer could be achieved by increasing the number of available transferrin receptors, and/or by increasing the turnover rate of transferrin at each receptor. The chemical form of the iron in transit through the trophoblast and the intracellular pathway are also unknown.

We have used rats to study these problems.

\section{Materials and Methods}

\section{Animals}

The experiments were performed on 4-month-old rats of a Wistar strain. Animals were mated overnight and pregnancy assessed from the presence of spermatozoa in the vagina next morning. This day was designated as Day 1. The rats were studied from Day 14 to 22 of pregnancy. Parturition usually occurred on Day 23.

\section{Isolation and labelling of proteins}

Rat transferrin and albumin were isolated as previously described (Morgan, 1966; Masters, Bignold \& Morgan, 1969). The purified transferrin was labelled with ${ }^{59} \mathrm{Fe}$ by adding iron-nitrilotriacetate in an amount just sufficient to saturate the specific iron binding sites. The ${ }^{59} \mathrm{Fe}$-labelled transferrin and the albumin were then labelled with ${ }^{125} \mathrm{I}$ and ${ }^{131} \mathrm{I}$, respectively, using the iodine monochloride method (McFarlane, 1963). Non-protein-bound radioactivity was removed from the proteins by gel filtration through Sephadex G-25. Radioactive isotopes were obtained from the Radiochemical Centre, Amersham, Bucks, U.K.

\section{Experimental procedure}

Transferrin and iron levels were estimated by injecting lightly anaesthetized (ether) pregnant animals, through a tail vein, with a mixture of ${ }^{59} \mathrm{Fe}-{ }^{125}$ I-labelled transferrin and ${ }^{131}$ I-labelled albumin. The rats were then allowed to recover, and $3 \mathrm{~h}$ later were re-anaesthetized. The abdomen was opened and a sample of blood taken from the abdominal aorta, using heparin as an anticoagulant. The fetuses, chorioallantoic and vitelline placentas and maternal livers were removed, washed in ice-cold $0.15 \mathrm{M}-\mathrm{NaCl}$, dried with tissues, and weighed. Radioactivity was counted in the fetuses, placentas, aliquots of livers, samples of maternal plasma and standards which were prepared from the injection mixture. In some of the Day 15 and later animals, the chorioallantoic placentas were separated into basal and labyrinthine parts which were weighed and counted separately. The values for protein-bound ${ }^{131} \mathrm{I}$ in plasma and placenta were used to calculate the amount of plasma in the placenta. This information and the total placental radioactivity were used to determine plasma levels of transferrin in the placenta and, hence, specifically bound transferrin as described previously (Baker \& Morgan, 1969). Radioactive iron levels in the placenta were also corrected for plasma iron to give values for cellular ${ }^{59} \mathrm{Fe}$ uptake by the placenta. Non-haem iron was estimated in fetal and placental tissues which had been homogenized in $0.15 \mathrm{M}-\mathrm{NaCl}$.

Fetectomy was performed on Day 20 of pregnancy in rats under ether anaesthesia. The abdomen was opened and half of the fetuses were removed through small incisions in the walls of the uterus, care being taken not to disturb the placentas. The uterus and the abdominal walls were then sutured. In most animals, the fetuses from one horn of the uterus were removed, leaving the other intact but, in some animals, alternate fetuses were removed. The pattern of results obtained with both types of procedure were identical. After fetectomy the dams were injected as above, killed at defined times and the uteri opened. The normal placentas, their attached fetuses and the remaining placentas were removed, washed, weighed and counted. 


\section{Microscopy}

For electron microscopy, samples of placenta were fixed in $2.5 \%$ glutaraldehyde in cacodylate buffer $\mathrm{pH} 7.5$ for $3 \mathrm{~h}$ at $4{ }^{\circ} \mathrm{C}$, and, for light microscopy, in formal saline $(10 \%$ formalin, $0.9 \% \mathrm{NaCl}$, $\mathrm{pH} 7.4$ ) for $3 \mathrm{~h}$ at $4^{\circ} \mathrm{C}$. For light microscopy, the tissue blocks were embedded in paraffin wax and sections were stained with haematoxylin and eosin and with Perl's Prussian blue stain. For electron microscopy, blocks were post-fixed in osmium tetroxide, dehydrated in a graded ethanol series, embedded in Araldite, sectioned and stained with lead citrate. Some sections were also stained with Perl's Prussian blue (Parmley, Spicer \& Alvarez, 1978). Grids were viewed in a Philip's 300 electron microscope.

\section{Analytical procedures}

Transferrin and albumin levels in maternal plasma were measured by radial immunodiffusion (Mancini, Carbonara \& Heremans, 1965) using monospecific antisera prepared in rabbits. Plasma iron was determined as recommended by the International Committee for Standardisation in Haematology. Placental total non-haem iron and its water-soluble (ferritin) and water-insoluble (haemosiderin) fractions were assayed colorimetrically (Kaldor, 1958). Protein uptake by tissues and fetuses was based on measurements of protein-bound radioactive iodine, estimated by precipitating the protein in homogenates with an equal volume of $10 \%$ trichloroacetic acid. Radioactivity was counted in a three-channel well-type $\gamma$-scintillation counter. Cross-counting correction was achieved by counting single isotope standards. Statistical significance was determined using the Student's $t$ test.

\section{Results}

The specific binding of transferrin by the chorioallantoic placenta increased progressively from 150 $\mu \mathrm{g} / \mathrm{g}$ on Day 14 to $530 \mu \mathrm{g} / \mathrm{g}$ on Day 20 (Text-fig. 1a). The increase in transferrin binding between Days 14 and 20 was even more pronounced, and the decrease between Days 20 and 22 less evident when the results were expressed per placental unit, rising from 13 to $108 \mu \mathrm{g} /$ placenta and then falling to $92 \mu \mathrm{g} /$ placenta (Text-fig. la). Most of the bound transferrin was associated with the labyrinth rather than with the basal layer. Near term (Days 18-21) values were $565 \pm 75 \mu \mathrm{g} / \mathrm{g}$ for the labyrinth compared to $108 \pm 65 \mu \mathrm{g} / \mathrm{g}$ for the basal layer (mean \pm s.e.m.; $n=12$ ). The percentage of the injected dose of radioiron present in the placenta as cellular ${ }^{59} \mathrm{Fe}$ is shown in Textfig. 1b. It increased from $0 \cdot 11 \%$ per placental unit at Day 14 to a maximum of $0.33 \%$ at Day 19 , decreasing to $0 \cdot 20 \%$ by Day 22 . When expressed per gram of placenta, the pattern is slightly different, with values ranging from $1.04 \% / \mathrm{g}$ at Day 15 to a maximum of $1 \cdot 24 \% / \mathrm{g}$ at Day 18 . The changes in transferrin binding by the placenta (Text-fig. 1a) were accompanied by similar changes in the rate of iron transfer (Text-fig. 1b). Radioiron incorporation in the fetus increased from $0 \cdot 2 \%$ of the injected dose at Day 14 to a maximum of $5 \cdot 6 \%$ per fetus at Day 20, decreasing to $3.2 \%$ at Day 22. The ratio of placental cellular ${ }^{59} \mathrm{Fe}$ to specifically bound transferrin decreased from Day 16 to Day 18, and then remained constant until parturition occurred on Day 23. In contrast, the ratio of total ${ }^{59} \mathrm{Fe}$ (i.e. placental plus fetal radioiron) to placental-bound transferrin increased over this period, due to a very marked rise in the fetal ${ }^{59} \mathrm{Fe}$ to transferrin ratio, from 0.021 at Day 16 to 0.056 at Day 17 (Text-fig. 1c). This ratio remained almost constant between Day 17 and 21 .

The transfer of albumin and transferrin to the fetus are shown in Text-fig. 1(d). Albumin values remained low throughout pregnancy, never exceeding $35 \mu \mathrm{g}$ per fetus $(70 \mu \mathrm{g} / \mathrm{g})$ until Day 21 , when it rose abruptly to a maximum of $1 \cdot 1 \mathrm{mg} /$ fetus $(250 \mu \mathrm{g} / \mathrm{g})$ at Day 22 , while transferrin transfer in the 3 $\mathrm{h}$ after injection increased from $6 \mu \mathrm{g} / \mathrm{fetus}(12 \mu \mathrm{g} / \mathrm{g})$ at Day 14 to $140 \mu \mathrm{g} / \mathrm{fetus}$ at Day $21(33 \mu \mathrm{g} / \mathrm{g})$ (Text-fig. 1d). This result agrees with the observations previously made by Morgan (1964). The value for albumin was equivalent to a transfer by each fetus of $0.01 \%$ of total circulating albumin 

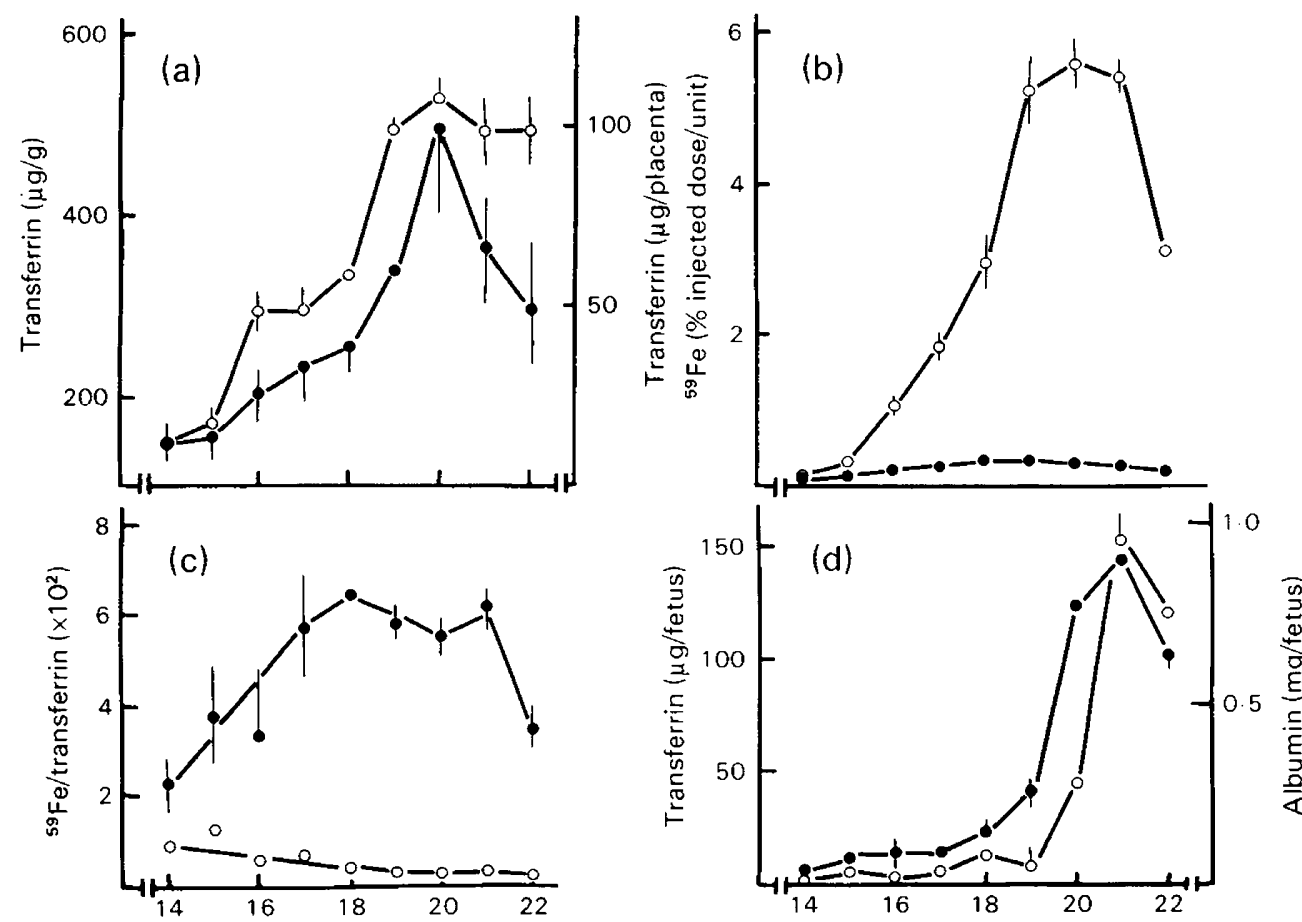

Days

Text-fig. 1. Amounts of transferrin, albumin and ${ }^{59} \mathrm{Fe}$ in rat placentas and fetuses during gestation. (a) Transferrin in the placenta expressed as $\mu \mathrm{g} / \mathrm{g}$ wet wt (O) and $\mu \mathrm{g} /$ placenta $(O)$; (b) ${ }^{59} \mathrm{Fe}$ in the placenta $(\mathrm{O})$ and fetus $(\mathrm{O}) ;(\mathrm{c})$ the ratio of ${ }^{59} \mathrm{Fe} /$ transferrin in the placenta $(\mathrm{O})$ and of total ${ }^{59} \mathrm{Fe} / \operatorname{transferrin}(\mathrm{O})$; (d) transferrin $(O)$ and albumin $(O)$ in the fetus. Values are mean \pm s.e.m. for 4 observations.

and the transferrin values were equivalent to $0.01 \%$ and $0.2 \%$ of total circulating transferrin on Days 14 and 21 , respectively.

Radioiron levels in the yolk sac decreased during pregnancy from $1.8 \%$ of the injected dose at Day 16 to $0.45 \%$ at Day 21 . Total transferrin binding values also decreased during this period, although albumin levels increased slightly, suggesting that there was no preferential transferrin binding by the yolk-sac placenta after Day 17.

\section{Placental iron uptake after fetectomy}

After fetectomy on Day 20, the placentas continued to accumulate radioactive iron for at least $20 \mathrm{~h}$ at the same rate as the controls, such that the sum of the radioactive iron in the normal placentas plus their attached fetuses at any one time was the same as the amount of iron in the placentas without fetuses (Text-fig. 2a; Table 2). Transferrin uptake by the placentas was not affected by fetectomy (Text-fig. 2b). The uptake of plasma iron by the placentas without fetuses was associated with an increase in placental non-haem iron (Table 1). The increase in iron levels did not inhibit iron uptake since placentas without fetuses still accumulated as much transferrinbound ${ }^{59} \mathrm{Fe}$ by $24 \mathrm{~h}$ after the operation as did the control fetuses (Table 1). Nearly all of the accumulated radioiron was found to be associated with the labyrinthine layer (Table 2).

After homogenization and differential centrifugation a mean of $89 \%$ of the radioactive iron was associated with the nuclear pellet and a further $10 \%$ with the mitochondrial fraction. The ability of different solubilizing agents to release radioactive iron from the nuclear pellet is shown in Table 3. 
Table 1. The concentration of non-haem iron in Day-20 rat placentas

\begin{tabular}{ccccc}
\hline $\begin{array}{c}\text { Time after } \\
\text { fetectomy } \\
(\mathrm{h})\end{array}$ & $\begin{array}{c}\text { Placenta } \\
\pm \text { fetus }\end{array}$ & $\begin{array}{c}\text { Ferritin } \\
\text { iron }(\mu \mathrm{g} / \mathrm{g})\end{array}$ & $\begin{array}{c}\text { Haemosiderin } \\
\text { iron }(\mu \mathrm{g} / \mathrm{g})\end{array}$ & $\begin{array}{c}\text { Total iron } \\
(\mu \mathrm{g} / \mathrm{g})\end{array}$ \\
\hline 4 & + & $18 \cdot 3 \pm 0 \cdot 1$ & n.d. & $18 \cdot 3 \pm 0 \cdot 1$ \\
& - & $14.5 \pm 1 \cdot 8^{* *}$ & $18 \cdot 8 \pm 3.9^{* *}$ & $33 \cdot 3 \pm 4 \cdot 9^{* *}$ \\
24 & + & $10 \cdot 8 \pm 0 \cdot 4$ & $4 \cdot 0 \pm 6 \cdot 4$ & $14 \cdot 8 \pm 7.4$ \\
& - & $14.0 \pm 2 \cdot 4^{*}$ & $29 \cdot 8 \pm 23 \cdot 7$ & $43.8 \pm 23.5$ \\
\hline
\end{tabular}

Values are the mean \pm s.d. of duplicate observation on 2 animals. n.d. none detected.

${ }^{*} P<0.05 ;{ }^{* *} P<0.01$.

Table 2. The effect of fetectomy on ${ }^{59} \mathrm{Fe}$ uptake in different parts of the Day-20 rat placenta

\begin{tabular}{lcc}
\hline \multicolumn{1}{c}{ Tissue } & $\begin{array}{c}\text { Placenta } \\
\pm \text { fetus }\end{array}$ & ${ }^{59} \mathrm{Fe}$ (c.p.m.) \\
\hline Basement layer & + & $45 \pm 9$ \\
Labyrinth & - & $57 \pm 15$ \\
& + & $313 \pm 23^{*}$ \\
Fetus & - & $3296 \pm 307^{*}$ \\
\hline
\end{tabular}

Values are mean \pm s.e.m. for 4 observations.

$* P<0.001$.

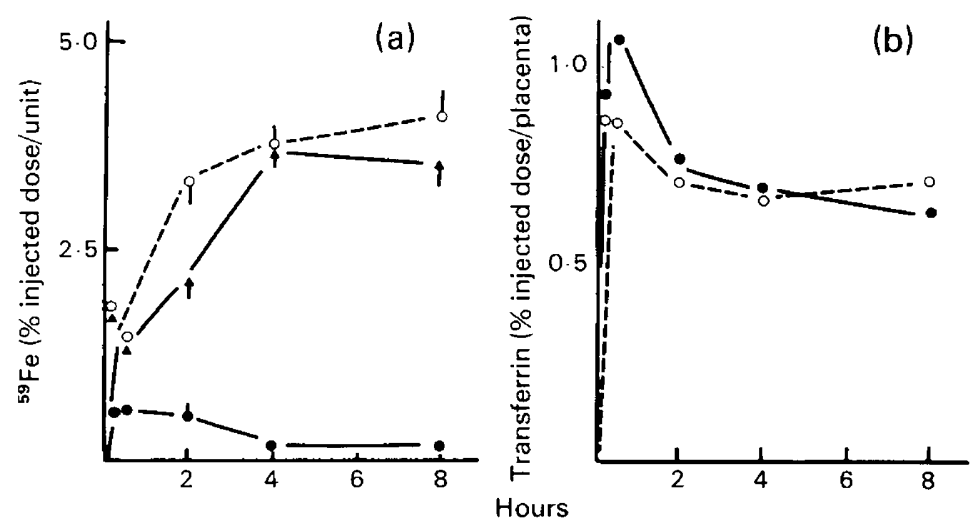

Text-fig. 2. Effect of fetectomy on (a) ${ }^{59} \mathrm{Fe}$ in placentas without fetuses $(\boldsymbol{\Delta})$, normal placentas $(O)$ and their attached fetuses $(O)$, and (b) transferrin binding by placentas with $(O)$ and without $(O)$ fetuses. Values are mean \pm s.e.m. for 3 observations.

Most agents released little iron from the pellet, suggesting that the iron is not membrane bound and that it may exist as deposits of insoluble ferric hydroxide.

\section{Light and electron microscopy}

No iron was detected in normal placentas using the Perl's Prussian blue reaction, but could be readily demonstrated in placentas without fetuses as early as $4 \mathrm{~h}$ after the operation. By $24 \mathrm{~h}$ the iron 
Table 3. The effect of different agents on the solubility of iron in placentas without fetuses

\begin{tabular}{lcc}
\hline \multicolumn{1}{c}{ Agent } & Concentration & $\left.\begin{array}{c}59 \\
\text { Fe in supernatant } \\
(\% \text { total }\end{array}{ }^{59} \mathrm{Fe}\right)$ \\
\hline Trypsin & $400 \mathrm{~g} / \mathrm{ml}$ & $7 \cdot 5$ \\
EGTA & $10 \mathrm{mM}$ & 8.0 \\
Acetic acid & $250 \mathrm{mM}$ & 17.0 \\
NaOH & $2 \mathrm{M}$ & 40.0 \\
DNAse & $50 \mathrm{~g} / \mathrm{ml}$ & 5.0 \\
$n$-Butanol & $0 \cdot 3 \%$ & $11 \cdot 0$ \\
SDS + ultrasonication $(30 \mathrm{sec})$ & $1 \% \%$ & 0 \\
Teric 12A9 & $5 \%$ & 3.0 \\
SDS & 5.0 \\
\hline
\end{tabular}

Placental homogenates were incubated at $37^{\circ} \mathrm{C}$ enzymes or at room temperature for $30 \mathrm{~min}$. After centrifugation for $30 \mathrm{~min}$ at $100000 \mathrm{~g}$ the supernatants and pellets were separated and counted. Values are the mean of two observations.

deposits had became more extensive and diffuse. The iron was mainly confined to the labyrinthine part of the placenta with little in the basal layer. Within the labyrinth, most of the iron was confined to the trophoblast cells. When the placentas without fetuses were examined under the electron microscope, clusters of electron-dense material were seen throughout the trophoblast layer. These clusters, which were not seen in control placentas, first appeared $4 \mathrm{~h}$ after fetectomy and became widespread $24 \mathrm{~h}$ later. Initially, they did not appear to be associated with any particular sub-cellular organelles, and there was no gradient in density from fetal to maternal faces of the placenta. At 24 $\mathrm{h}$, crystals were found around the nuclei and associated membranes within the cytoplasm. These were positively identified as iron by the presence of cuboid deposits following exposure to Perl's Prussian blue stain (Parmley et al., 1978).

\section{Discussion}

The results presented in this paper indicate that the increase in placental transfer of iron which occurs in the last third of gestation in the rat is due to an increase in transferrin receptor numbers rather than to an increase in the rate of cycling of the transferrin receptors. Assuming that the amount of transferrin bound at the time of excision is proportional to the number of receptors, then the number increased by a factor of 9 between Day 14 and Day 20. Most of the increase occurs in the labyrinth rather than in the basal layer, supporting the theory that it is the labyrinth that is involved in transport, while the basal layer functions as an endocrine organ (Deane, Rubin, Driks, Lobel \& Leipsner, 1962; Botte, Materazzi \& Chieffi, 1966). However, during this period, the maternal surface area of the placenta increases from $3.8 \mathrm{~cm}^{2}$ in Day 14 rats to $168 \mathrm{~cm}^{2}$ in Day 23 rats, a 54-fold increase (Webb \& Bruce, 1980). This would suggest that the number of receptors per unit surface area actually decreases during gestation. Since, at present, it is not known which cells in the placenta are involved in iron transport, and since the maternal surface area measurement does not discriminate between the different cell types, it is possible that the discrepancy may be explained in terms of differential cell growth during gestation.

The ratio of ${ }^{59} \mathrm{Fe}$ in the placenta to transferrin decreased from Day 14 to 17 of gestation (Textfig. 1c). Iron released from transferrin can either be transported directly to the fetus or held within the trophoblast cells as ferritin or perhaps bound to cytoplasmic carriers. The change in ratio 
suggests that, at Day 14, less of the iron taken up by the placenta is transferred directly to the fetus than at later stages. As the transfer system matures the iron is diverted from these pathways and is transported directly to the fetus. In contrast, the ratio of total (fetal plus placental) ${ }^{59} \mathrm{Fe}$ to transferrin increases during pregnancy, reaching maximal values at about Days 17-18 (Text-fig. 1c). This result suggests that the mechanism involved in the release of iron from transferrin also matures, becoming more efficient between Days 14 and 17, and remaining relatively constant until just before parturition. Thus, three separate stages in the transport process develop in parallel with the growth of the fetus: (1) the number of transferrin receptors increases to reach a maximum on Day 20, (2) between Days 14 and 17, the iron release mechanism develops so that more of the transferrin taken up releases its iron to the placenta and (3) the iron transfer system matures so that iron is not diverted to auxiliary pathways, but is transferred directly to the fetus.

In contrast to that in the chorioallantoic placenta, iron and transferrin uptake in the yolk sac decreases with gestational age. The role of the yolk sac placenta in iron uptake is uncertain. Nylander (1953) and Magnusson, Bergstrom \& Odeblad (1955) demonstrated iron accumulation and the present data show that transferrin is bound to the yolk sac placenta in greater amounts than to the chorioallanoic placenta at earlier stages of pregnancy (Text-fig. 2b). This evidence suggests that the yolk sac may play an important part in iron transport, at least during this time, but the present results, and those of Davies, Brown, Stewart, Terry \& Sison (1959) indicate that it is unlikely to be of physiological importance in iron transfer during the later stages of pregnancy. Further evidence against the role of the yolk sac in iron uptake is provided by the fetectomy experiments.

It was originally thought that fetectomy had little effect on the morphology and function of the placenta (Klein, 1935; Selye, Collip \& Thomson, 1945), but more recent evidence suggests otherwise (Davies \& Glasser, 1968; Petropolous, 1973). For the first 2 days after fetectomy, the placenta continues to grow and differentiate normally, but by 4 days, there are signs of degeneration of the trophoblast. The cells of the the basal layer survive better than those of the labyrinth, an observation which may be correlated with the maintenance of the placenta as an endocrine organ after fetectomy (Deane et al., 1962; Botte et al., 1966; Davies, Davenport, Norris \& Rennie, 1966; Davies \& Glasser, 1968; Petropolous, 1973). After fetectomy, the placenta continues to accumulate iron at approximately the same rate as the controls for at least $28 \mathrm{~h}$ (Text-fig. 2a). These results extend those of previous workers who had studied the effects of fetectomy on the function of the haemochorial placenta for up to $4.5 \mathrm{~h}$ after operation (Bothwell et al., 1958; Lane, 1968; Davies \& Glasser, 1968; McLaurin \& Cotter, 1967; Wong \& Morgan, 1973). Iron accumulation by the placenta appears to be an irreversible process, with little or no refluxing of the ${ }^{59} \mathrm{Fe}$ back to maternal blood. There also seems to be no control over iron uptake by the placenta in relation to fetal needs since, $24 \mathrm{~h}$ after fetectomy, iron uptake is still active in all placentas (see also Nylander, 1953; Lane, 1968). Hence, the results of the present and earlier fetectomy experiments indicate that the iron transport process cannot be modified by either the fetus or the placenta, but is 'preprogrammed' into the genetic profile of the trophoblast cell.

Iron deposits were seen in the placenta as early as $4 \mathrm{~h}$ after fetectomy, indicating that the iron is diverted from its normal pathway to the fetus and is converted to 'haemosiderin' iron. There did not appear to be any particular gradient in cluster formation, with iron deposits occurring first on the fetal face of the placenta, and then later towards the maternal side. Although iron was occcasionally seen associated with nuclear and other membrane systems, solubilizing the membranes did not effect iron release. The formation of haemosiderin is likely to be responsible, at least in part, for the pathological changes seen in the placenta after removal of the fetus.

We thank Mr Alan Light for help with the preparation of specimens for histology. H.J.M. gratefully acknowledges financial support from the Raine Foundation. 


\section{References}

Baker, E. \& Morgan, E.H. (1969) The role of transferrin in placental iron transfer in the rabbit. $Q$. $J l \exp$. Physiol. 54, 173-186.

Baker, E. \& Morgan, E.H. (1970) Iron transfer across the perfused rabbit placenta. Life Sci. 9, 765-772.

Bothwell, T.H., Pribilla, W.F., Mebust, W. \& Finch, C.A. (1958) Iron metabolism in the pregnant rabbit: iron transfer across the placenta. Am. J. Physiol. 193, 615622.

Botte, V., Materazzi, G. \& Chieffi, G. (1966) Histochemical distribution of $3 \beta$-hydroxysteroid dehydrogenase and $17 \alpha-$ and $17 \beta$-hydroxysteroid dehydrogenases in the placenta and foetal membranes of the rat. J. Endocr. 34, 179-183.

Davies, J. \& Glasser, S.R. (1968) Histological and fine structural observations on the placenta of the rat. II. Changes after the surgical removal of the fetus. Acta anat. 69, 575-608.

Davies, J., Brown, E.B., Stewart, D., Terry, C.W. \& Sison, J. (1959) Transfer of radioactive iron via the placenta and accessory fetal membranes in the rabbit. $A m$. J. Physiol. 197, 87-92.

Davies, J., Davenport, G.R., Norris, J.L. \& Rennie, P.I.C. (1966) Histochemical studies on hydroxysteroid dehydrogenase activity in mammalian reproductive tissues. Endocrinology 78, 667-671.

Deane, H.W., Rubin, B.L., Driks, E.C., Lobel, B.L. \& Leipsner, G. (1962) Trophoblastic giant cells in placentas of rats and mice and their probable role in steroid-hormone production. Endocrinology 70, 407419.

Fletcher, J. \& Suter, P.E.N. (1969) The transport of iron by the human placenta. Clin. Sci. 36, 209-220.

Glasser, S.R., Wright, C. \& Heyssel, R.M. (1968) Transfer of iron across the placenta fetal membrane in the rat. Am. J. Physiol. 215, 205-210.

Hershko, C., Cohen, H. \& Zajicek, G. (1976) Iron mobilization in the pregnant rat. $\mathrm{Br}$. J. Haematol. 33, 505516.

Kaldor, I. (1958) Studies on intermediary iron metabolism. XII. Measurement of iron derived from water soluble and water insoluble non haem compounds (ferritin and haemosiderin iron) in the liver and spleen. Aust. J. exp. Biol. Sci. 36, 173-182.

Klein, M. (1935) Recherches sur le rôle du placenta dans l'arret du cycle ovarien au course du la grossesse. $C$. $r$. Séanc. Soc. Biol. 49, 579-590.

Lane, R.S. (1968) Regulating factors in the transfer of iron across the placenta. Br. J. Haematol. 15, 365369.

Loh, T.T., Higuchi, D.A., van Bockxmeer, F.M., Smith, C.H. \& Brown, E.B. (1980) Transferrin receptors on the human placental microvillous membrane. $J$. clin. Invest. 65, 1182-1191.
Magnusson, G., Bergstrom, I. \& Odeblad, E. (1955) Studies on uptake of Fe59 in rat embryo, placenta, uterus and mammary gland. Acta radiol. 42, 227-232.

Mancini, G., Carbonara, A.O. \& Heremans, J.F. (1965) Immunochemical quantitation of antigens by single radial immunodiffusion. Immunochemistry 2, 235254.

Masters, C.L., Bignold, L.P. \& Morgan, E.H. (1969) Plasma protein metabolism and transfer to the fetus during pregnancy in the rat. Am. J. Physiol. 216, 876 883.

McFarlane, A.S. (1963) Efficient iron labelling of proteins with iodine. Nature, Lond. 182, 53.

McLaurin, L.P. \& Cotter, J.R. (1967) Placental transfer of iron. Am. J. Obstet. Gynec. 98, 931.

Morgan, E.H. (1964) Passage of transferrin, albumin and gamma-globulin from maternal plasma to the foetus in the rat and rabbit. J. Physiol., Lond. 171, 26-41.

Morgan, E.H. (1966) Transferrin and albumin turnover in the rat. Am. J. Physiol. 211, 1486-1494.

Nylander, G. (1953) On the placental transfer of iron: an experimental study in the rat. Acta physiol. scand. 29, Suppl. 107, 1-105.

Parmley, R.T., Spicer, S.S. \& Alvarez, C.J. (1978) Ultrastructural localization of non heme cellular iron with ferrocyanide. J. Histochem. Cytochem. 26, 729-741.

Petropolous, E.A. (1973) Maternal and fetal factors affecting the growth and function of the rat placenta. Acta endocr., Copenh., Suppl. 176, 9-55.

Seal, U.S., Sinha, A.A. \& Doe, R.P. (1972) Placental iron transfer: relationship to placental anatomy and phylogeny of the mammals. Am. J. Anat. 134, 263-369.

Selye, H., Collip, J.B. \& Thomson, D.L. (1945) Endocrine interrelations during pregnancy. Endocrinology 19, 151-159.

van Bockxmeer, F., Hemmaplardh, D. \& Morgan, E.H. (1975) Studies on the binding of transferrin to cell membrane receptors. Proteins of iron storage and transport. In Biochemistry and Medicine, pp. 111-119. Ed. R. R. Crichton. Elsevier, New York.

Vosburgh, G.J. \& Flexner, L.N. (1950) Maternal plasma as a source of iron for the foetal guinea pig. $A m . J$. Physiol. 161, 202-211.

Webb, S. \& Bruce, N. (1980) The relationship of foetal weight to placental weight, blood flow and surface areas of the placental exchange membrane at different stages of gestation in rats. Proc. Aust. Soc. Rep. Biol. 12, 77, Abstr.

Wong, C.J. \& Morgan, E.H. (1973) Placental transfer of iron in the guinea pig. Q. Jl exp. physiol. 58, 47-58.

Received 1 February 1982 